\title{
Inventory Model with Fixed Shelf Life under Generalized Non-Increasing Demand
}

\author{
Han-Wen Tuan, Kuo-Chen Hung and Gino K. Yang * \\ Department of Multimedia Game Development and Application, Hungkuang University, Taichung City 43302, \\ Taiwan; dancathy@hk.edu.tw (H.-W.T.); kchung@hk.edu.tw (K.-C.H.) \\ * Correspondence: yangklung@hk.edu.tw; Tel.: +886-9-3786-8127
}

\begin{abstract}
In this paper, we develop an economic order quantity (EOQ) model for fixed shelf-life items and a non-increasing demand. The objective of this model is to maximize the total profit. We find the criterion to decide (i) the interior maximum solution or (ii) the boundary maximum solution. Eight numerical examples are given to illustrate all possible scenarios of this generalized model. Our results identify a scenario for which the maximum profit is always negative. This is highly relevant for firms in the public sector operating at a financial loss.
\end{abstract}

Keywords: inventory; non-increasing demand; shelf-life; expiry date

check for updates

Citation: Tuan, H.-W.; Hung, K.-C.; Yang, G.K. Inventory Model with Fixed Shelf Life under Generalized Non-Increasing Demand. Mathematics 2021, 9, 2735. https://doi.org/ $10.3390 /$ math9212735

Received: 17 October 2021 Accepted: 23 October 2021 Published: 28 October 2021

Publisher's Note: MDPI stays neutral with regard to jurisdictional claims in published maps and institutional affiliations.

Copyright: (c) 2021 by the authors. Licensee MDPI, Basel, Switzerland. This article is an open access article distributed under the terms and conditions of the Creative Commons Attribution (CC BY) license (https:// creativecommons.org/licenses/by/ $4.0 /)$.

\section{Introduction}

There are many research topics that are related to inventory management. For example, Sarkar et al. [1] and Quezada-Téllez et al. [2] studied inventory management in society. Lee et al. [3] and Zimpel-Leal, and Lettice [4] considered industry. Rubio-Valdehita et al. [5] and Górska-Warsewicz et al. [6] examined retailing companies. Gładysz et al. [7] and Orynycz et al. [8] presented lean management. De Giovanni [9] and Malik, and Sarkar [10] developed supply chain philosophies. Inventory management depends on the type of product that a firm retails. Stable products have no expiration date, while perishable products feature a limited time range, gradually losing their value over time. Whereas perishable products, such as fresh fish, lose their value steadily, others, such as milk, have a fixed shelf life. Before the expiry date is reached, these products do not change in appearance, taste, texture, or flavor. There exists a large body of research on inventory models for products with a fixed shelf life. Most inventory models dealing with deteriorated items have a constant decay rate. For example, Lin et al. [11] developed a production inventory model with the constant deteriorated date and the production rate dependent on demand and inventory level, and Yang et al. [12] studied an inventory model with a constant decay rate proportional to the inventory level. In these models, a dichotomous shelf-life effect for perishable items is assumed. The item is either as good as brand-new or the item is deteriorated and cannot be used. However, this assumption is not reasonable in some situations. An obvious case is an agricultural product. The quality of products perceived by consumers may be reduced within the shelf-life duration. They may purchase substitute products or brands offering a later expiry date. The demand reaches the maximum when the product is fresh and declines as time goes on. Just a few inventory models considered perishable items with a fixed shelf-life. The current paper is based on the work of Avinadav and Arponen [13], who considered the effect of perceived quality, using a declining demand rate, which is dependent on the time until the expiry date. When an item is fresh, its perceived quality is considered perfect. They constructed an inventory model with polynomial-type demand which is proportional to the remaining time to full shelf-life duration. The research gap is that Avinadav and Arponen [13] provided those numerical examples with negative maximum profit. It seems trivial that for an example of a maximum profit inventory model obtains a negative profit then this example or the computation of this numerical example 
must contain errors. However, Avinadav and Arponen [13] informed researchers that they examined 729 numerical examples to find 255 examples with negative maximum profits, and then they discard those 255 examples. For the remaining 474 examples with positive maximum profits, Avinadav, and Arponen [13] execute sensitivity analysis. In this paper, we will provide theoretical evidenceto show that under two conditions of Theorem 2 , obtaining a negative maximum profit is reasonable.

Up to now, 26 papers have cited Avinadav and Arponen [13] in their references. We will provide a brief discussion of those 26. Avinadav et al. [14] expanded this inventory system to derive the optimal order quantity, price, and replenishment cycles for a demand that is linearly dependent on price and time. We recall that Avinadav and Arponen [13] considered the polynomial type demand $\lambda(t)$ and then Avinadav et al. [14] extended to $\lambda(t, p)$ where $p$ is the selling price such that $\lambda(t, p)$ is the multiplication of a polynomial type function in $t$ and a linearly decreasing function in $p$. Leśniewski and Bartoszewicz [15] study inventory models with defect items, warehouse capacity, and deterioration during storage in a warehouse under the bullwhip effect and supply chain. Aiello et al. [16] constructed a mathematical model to optimize the food supply chain consist of retailers and potential recipients that operate the food recovery to include the benefits of donors and the operational charges for the food recovery. Avinadav [17] studied periodic inventory models to revise a classical newsvendor system such that the holding cost is related to the stock levels within the selling period to optimize the expected profit. Avinadav et al. [18] further generalized this approach so that generalized demand is the multiplication of a decreasing function and a linearly decreasing function. However, Lemma 1 of Avinadav et al. [18] is questionable, as its proof is based on the existence of an interior optimal solution. In Section 3, this paper will provide a reasonable explanation for the restriction. In Avinadav et al. [14] and Avinadav et al. [18], they cannot prove the uniqueness of the optimal solution and they were not aware that sometimes the optimal solution occurs at the boundary. Herbon [19] examined an inventory model with a perishable product with a fixed shelf life, and a dynamic pricing policy to study consumer sensitivity to price and freshness. Aiello et al. [20] developed a food supply chain for food recovery policies to find the optimal time to remove perishable items from the shelves and then decided to the livestock market or donated organizations. Chuang and Lin [21] studied a two-echelon inventory model with a supplier and one retailer to decide the optimal solutions for selling price under a fixed shelf-life and a ramp type demand with shortages. Ma [22] analyzed the maximization of profit for fresh products with two quality levels by a consumer utility function to solve the optimal solutions for ordering quantity and selling price. Muriana [23] considered a food supply chain product with an uncertain shelf life that could be withdrawn and shipped to alternative destinations. Avinadav [24] considered a stochastic periodic-review inventory system to investigate its relation to the classical newsvendor problems and then derived several approximated solutions by a Brownian motion demand process. Muriana [25] developed a deterioration model with a stochastic demand following a normal distribution for open-dating foods with a shelf life. Yamazaki et al. [26] analyzed safety stock and cycle stock to study the relationship between fluctuation stock and safety stock under various cases of differences between supply and demand. Avinadav et al. [27] constructed a new inventory system with deteriorated items to determine the optimal promotion expenditures, ordering quantity, selling price, and cycle length. Demirag et al. [28] built an economic order quantity model with a decreasing demand, expired date, and a linear expression that is closely related to Avinadav and Arponen [13]. Demirag et al. [28] obtained a cubic polynomial for the optimal cycle length and then they derived three formulated candidates for the optimal solution to replace the numerical approximated approach proposed by Avinadav and Arponen [13]. Muriana [29] tried to diminish the influence of production losses along the supply chain when demand is restricted by various economic, political, climatic, and legal factors. Sharma et al. [30] studied partial backlogging policy when demand is dependent on selling price and expiry date. Chernonog and Avinadav [31] considered a two-echelon supply chain consisting of a leader (manufacturer) and a follower 
(retailer) where the demand is related to investment in advertising, product age, and price. Hanukov et al. [32] developed a combined queueing and inventory system to consider inventory management techniques and time management policies simultaneously for the fast-food industry. They obtained the steady-state probabilities by matrix geometric methods to decide the optimal level of investment in preservation technologies and the optimal preliminary services capacity. Lin et al. [33] examined a system to the reserves and procurement management for humanitarian logistics by sensitivity analyses and numerical examples to reveal managerial insights and then provided practical suggestions for the government. Avinadav [34] formulated a two-echelon supply chain with a manufacturer and a retailer to examine conditions where the demand is related to the age of the product on a shelf-life, sales effort, and selling price. Chernonog [35] developed a two-echelon supply chain consisting of a manufacturer and a retailer under a Stackelberg game to decide the investment in advertising, cycle length, and the selling price. He studied two cases: retailer-leader and manufacturer-leader to derive relations between advertising investment and cycle length. Hanukov et al. [36] constructed service models for the fastfood market for fastidious or strategic customers for fresh items or pre-prepared items under different prices to optimize the expected profit. Krommyda et al. [37] developed a maximum profit inventory model in which products that are near their expiry date are reduced in price, donated to charity, or sold to the livestock market. Muriana [38] examined inventory models for deteriorated items with Weibull perishable rate to consider the relationship between the characteristic life and the perishable rate to locate the optimal solution. Hanukov et al. [39] developed a multi-server model to short sojourn time that servers will use their idle time to make partially prepared items. They applied a Markovian queueing method to derive closed-form solutions for the entries of the rate matrix.

In this paper, we extend the inventory model of Avinadav and Arponen [13] from a special form of polynomial type demand to a generalized version of any non-increasing demand. We further prove the existence and uniqueness of the optimal solution for our new inventory model. We also identify the criterion for determining whether the optimal solution is an interior or a boundary point. Moreover, when the optimal solution occurs at the boundary point, we prove that the maximum profit is always negative. This finding is relevant to firms in the public sector operating at a financial loss.

The remainder of this paper is organized as follows. In Section 2, we provide a literature review to compare our new model with those existing systems to demonstrate our contributions. In Section 3, we present the notation and assumptions which constitute the framework of this paper. In Section 4, we review the solution procedure of Avinadav and Arponen [13]. We derive an extension and then demonstrate our improvements in Section 5. In Section 6, we show that our findings can be applied to Avinadav and Arponen [13] and Avinadav et al. [14]. In Section 7, we present eight examples of the proposed generalized inventory model. In Section 8, we discuss several directions for future research and managerial insights of our paper. Section 9 presents our conclusion.

\section{A Literature Review among Models}

We list comparisons among our new model and those existing systems to illustrate our contribution to the academic society (Table 1). 
Table 1. Comparisons among models.

\begin{tabular}{|c|c|c|c|c|c|c|c|c|}
\hline & S1 & $\mathbf{B}$ & $\mathbf{L}$ & S2 & P1 & S3 & $\mathbf{W}$ & P2 \\
\hline Aiello et al. [16] & & & & & & & $\checkmark$ & \\
\hline Aiello et al. [20] & & & & & & & $\checkmark$ & \\
\hline Avinadav [34] & & & & $\checkmark$ & & & & $\checkmark$ \\
\hline Avinadav and Arponen [13] & & & & & & $\checkmark$ & & \\
\hline Avinadav et al. [14] & & & & & $\checkmark$ & & & $\checkmark$ \\
\hline Avinadav et al. [18] & & & & & $\checkmark$ & & & \\
\hline Avinadav et al. [27] & & & & & $\checkmark$ & & & $\checkmark$ \\
\hline Bhuiya et al. [40] & & $\checkmark$ & & & & & & \\
\hline Chernonog [35] & & & & $\checkmark$ & & & & $\checkmark$ \\
\hline Chernonog andAvinadav [31] & & & & $\checkmark$ & $\checkmark$ & & & $\checkmark$ \\
\hline Chuang and Lin [21] & & & & & & $\checkmark$ & & $\checkmark$ \\
\hline De Giovanni [9] & $\checkmark$ & & & & & & & \\
\hline Demirag [28] & & & & & & $\checkmark$ & & \\
\hline Ganguly et al. [41] & & & & $\checkmark$ & $\checkmark$ & & & \\
\hline Gładysz et al. [7] & & & $\checkmark$ & & & & $\checkmark$ & \\
\hline Hanukov et al. [32] & & & & & & & & $\checkmark$ \\
\hline Hanukov et al. [36] & & & & & & & & $\checkmark$ \\
\hline Herbon [19] & & & & & $\checkmark$ & & & \\
\hline Hota et al. [42] & & & & $\checkmark$ & & & & \\
\hline Khan et al. [43] & & & & $\checkmark$ & & & & \\
\hline Kim et al. [44] & & $\checkmark$ & & & & & & \\
\hline Krommyda et al. [37] & & & & & & $\checkmark$ & & \\
\hline Lee et al. [3] & $\checkmark$ & & & & & & & \\
\hline Leśniewski and Bartoszewicz [15] & & & & & & & & $\checkmark$ \\
\hline Lin et al. [11] & & $\checkmark$ & & & & & & $\checkmark$ \\
\hline Ma [22] & & & & & $\checkmark$ & & & \\
\hline Malik and Sarkar [10] & $\checkmark$ & & & & & & & \\
\hline Mishra et al. [45] & $\checkmark$ & & & & & & & \\
\hline Muriana [23] & & & & & & $\checkmark$ & $\checkmark$ & \\
\hline Muriana [25] & & & & & & $\checkmark$ & & $\checkmark$ \\
\hline Muriana [29] & & & & & & & $\checkmark$ & \\
\hline Muriana [38] & & & & & & & & $\checkmark$ \\
\hline Orynycz et al. [8] & & & $\checkmark$ & & & & & \\
\hline Sarkar et al. [1] & $\checkmark$ & $\checkmark$ & & & & & & \\
\hline Sharma et al. [30] & & & & & & & & $\checkmark$ \\
\hline Taleizadeh et al. [46] & & & & & $\checkmark$ & & & \\
\hline Yang et al. [12] & & $\checkmark$ & & & & & & $\checkmark$ \\
\hline Zimpel-Leal and Lettice [4] & $\checkmark$ & & & & & & & \\
\hline Sarkar [47] & & & & & $\checkmark$ & & & $\checkmark$ \\
\hline Sarkar [48] & & & & & $\checkmark$ & & & $\checkmark$ \\
\hline Sepehri et al. [49] & $\checkmark$ & & & & $\checkmark$ & & & $\checkmark$ \\
\hline This study & & & & & & $\checkmark$ & & \\
\hline
\end{tabular}

Abbreviations for the first row: S1: Sustainable; B: Backordering; L: Lean management; S2: Supply chain; P1: Pricing; S3: Shelf-life; W: Waste management; P2: Perishable. 
When we constructed Table 1, we find six related papers: Ganguly et al. [41], Hota et al. [42], Khan et al. [43], Kim et al. [44], Mishra et al. [45], and Taleizadeh et al. [46] such that we add those six papers to our comparison. Based on the above table, we provide a literature review to compare our new model with those existing systems to demonstrate our contributions.

\section{Notation and Assumptions}

In Avinadav and Arponen [13], Avinadav et al. [14], and Avinadav et al. [18], they used different notation. To be compatible with Avinadav and Arponen [13], we will apply the same notation and assumptions as they used in Avinadav and Arponen [13].

The notation used in Avinadav and Arponen [13]:

$n$ : the power for the polynomial type demand proposed by Avinadav and Arponen [13];

$t$ : time elapsed from the beginning of the last replenishment.

$T_{0}:$ the full shelf-life duration of the item.

$\lambda(t):$ the demand rate of the item at a time $t$.

$c:$ the purchasing cost of the item.

$p$ : the selling price of the item.

$h$ : the holding cost per unit, per unit of time.

$K$ : the ordering cost per order.

$T$ : the cycle length (i.e., the time between sequential replenishments), which is a decision variable;

$Q:$ the order quantity, which is a function of $T$.

$\pi$ : the average profit.

$A=\left(p-c-\frac{h T_{0}}{n+2}\right) \frac{\lambda_{0} T_{0}}{n+1}$ : an abbreviation to simplify the expression that was defined by Avinadav and Arponen [13].

They proposed the following five assumptions:

(1) All units in the arriving order have a full and fixed shelf-life duration.

(2) Units that have passed their expiry date have no demand.

(3) Replenishments are instantaneous and the lead time effect is neglected.

(4) Shortages are not allowed.

(5) In Avinadav and Arponen [13], the demand rate is expressed as a polynomial function that decreases with time. In this paper, we extend the demand rate to any positive, non-increasing function.

Avinadav and Arponen [13] assumed that demand has a decreasing polynomial form, with the following demand rate:

$$
\lambda(t)=\lambda_{0}\left(1-\frac{t}{T_{0}}\right)^{n}, \text { for } 0 \leq t \leq T_{0}
$$

where $\lambda_{0}$ is the initial demand rate with $\lambda_{0}=\lambda(0)$. We extend this to arbitrary nonincreasing demand.

Cycle length $T$ has three restrictions: (a) $T>0$ if the decision-maker seeks to maximize profit, (b) $T \leq T_{0}$ that is, the full shelf-life duration, $T_{0}$, is an upper bound for the cycle length, and (c) $T \leq(p-c) / h$ so that gross profit per unit is not less than maximum holding cost $T h$, there by guaranteeing a profit on each item sold.

This represents a maximum profit inventory model. $h T \leq p-c$ means that the selling price should not be less than the purchasing cost plus the maximum holding cost. If the maximum solution $T_{a}$ satisfies $h T_{a}>p-c$, then we know that for all items sold during $T \in\left((p-c) / h, T_{a}\right]$, the net profit is negative. Hence, the replenishment cycle should be shortened from $\left(0, T_{a}\right]$ to $(0,(p-c) / h]$. This shows that the restriction $h T \leq p-c$ is reasonable. 


\section{Model Proposed by Avinadav and Arponen (2009)}

In the considered system, shortages are not allowed and old items have no demand after new items arrive. Therefore, at the end of the replenishment cycle, the inventory level drops to zero and the order quantity is derived as follows:

$$
Q=\int_{0}^{T} \lambda(t) d t
$$

to derive the order quantity

$$
Q=\frac{\lambda_{0} T_{0}}{n+1}\left(1-\left(1-\frac{T}{T_{0}}\right)^{n+1}\right) .
$$

Without deterioration, the inventory level is obtained as follows:

$$
I(t)=\int_{t}^{T} \lambda(s) d s,
$$

to obtain the inventory level

$$
I(t)=\frac{\lambda_{0} T_{0}}{n+1}\left(\left(1-\frac{t}{T_{0}}\right)^{n+1}-\left(1-\frac{T}{T_{0}}\right)^{n+1}\right) .
$$

Average profit is derived as follows:

$$
\pi(T)=\frac{1}{T}\left[(p-c) Q-K-h \int_{0}^{T} I(t) d t\right]
$$

to find that

$$
\pi(T)=\left(\frac{h \lambda_{0} T_{0}}{n+2}-\frac{A}{T}\right)\left(1-\frac{T}{T_{0}}\right)^{n+1}+\frac{A-K}{T},
$$

where $A=\left(p-c-\frac{h T_{0}}{n+2}\right) \frac{\lambda_{0} T_{0}}{n+1}$ is an abbreviation to simplify the expression, for the domain $T \leq \min \left\{T_{0}, \frac{p-c}{h}\right\}$. They assumed an auxiliary function $G(T)$ satisfying $\frac{d}{d T} \pi(T)=\frac{G(T)}{T^{2}}$ yielding

$$
G(T)=\left(1-\frac{T}{T_{0}}\right)^{n}\left(-\frac{n+1}{n+2} h \lambda_{0} T^{2}+\frac{n A}{T_{0}} T+A\right)-(A-K),
$$

for $T<\min \left\{T_{0},(p-c) / h\right\}$. In Lemma 3.1 of Avinadav and Arponen [13], they mentioned that $G(T)$ is a decreasing function for $T<\min \left\{T_{0}, \frac{p-c}{h}\right\}$.

In Appendix A of Avinadav and Arponen [13], they showed that

$$
\frac{d G(T)}{d T}=(n+1) \frac{h \lambda_{0}}{T_{0}} T\left(1-\frac{T}{T_{0}}\right)^{n-1}\left(T-\frac{T_{0}+n((p-c) / h)}{n+1}\right) .
$$

They further defined expression $T_{1}$ as follows:

$$
T_{1}=\frac{1}{n+1} T_{0}+\frac{n}{n+1} \frac{p-c}{h} .
$$

This expression is a linear combination of two upper bounds $T_{0}$ and $\frac{p-c}{h}$. Because $T<\min \left\{T_{0}, \frac{p-c}{h}\right\}$ we know that $T<T_{1}$ and obtain

$$
\frac{d G(T)}{d T}<0
$$


This completed the proof provided by Avinadav and Arponen [13] to verify that $G(T)$ is a decreasing function.

\section{Proposed Modification}

We extend the inventory model proposed by Avinadav and Arponen [13] from polynomial-type decreasing demand to any non-increasing demand.

Because shortages are not allowed, the ordering quantity is derived from $Q=$ $\int_{0}^{T} \lambda(t) d t$ where $\lambda(t)$ is the demand and the gross profit is $(p-c) Q$. The inventory level at the time $t$ is derived by $I(t)=\int_{t}^{T} \lambda(s) d s$, and the total holding cost is obtained as:

$$
h \int_{0}^{T} I(t) d t=h \int_{0}^{T} \int_{t}^{T} \lambda(s) d s d t
$$

We derive average profit

$$
\pi(T)=\frac{1}{T}\left[(p-c) \int_{0}^{T} \lambda(s) d s-K-h \int_{0}^{T} \int_{t}^{T} \lambda(s) d s d t\right],
$$

under three conditions: $T>0, T \leq \frac{p-c}{h}$, and $T \leq T_{0}$.

We assume an auxiliary function, $H(T)$, satisfying $\frac{d}{d T} \pi(T)=\frac{H(T)}{T^{2}}$. Based on Leibniz's rule, we imply that:

$$
\frac{\partial}{\partial T} \int_{0}^{T} \int_{t}^{T} \lambda(s) d s d t=1 \cdot M(T, T)-0 \cdot M(T, 0)+\int_{0}^{T} \frac{\partial}{\partial T} M(T, t) d T,
$$

where $M(T, t)=\int_{t}^{T} \lambda(s) d s$, with $\frac{\partial}{\partial T} M(T, t)=\lambda(T)$ and $\int_{0}^{T} \lambda(T) d t=T \lambda(T)$. Hence, we find

$$
H(T)=T \lambda(T)[(p-c)-h T]-(p-c) \int_{0}^{T} \lambda(s) d s+K+h \int_{0}^{T} \int_{t}^{T} \lambda(s) d s d t
$$

under three conditions: $T>0, T<\frac{p-c}{h}$, and $T<T_{0}$.

Applying Leibniz's rule again, we derive that

$$
\frac{d}{d T} H(T)=T\left[(p-c-h T) \frac{d \lambda(T)}{d T}-h \lambda(T)\right] .
$$

Because demand $\lambda(T)$ with $\lambda(T)>0$ and $\lambda(T)$ is a non-increasing function (i.e, $\left.\frac{d \lambda(T)}{d T} \leq 0\right)$, we obtain

$$
\frac{d}{d T} H(T)<0
$$

If we compare Equations (11) and (17) under generalized demand, we still obtain the property proposed in Lemma 3.1 of Avinadav and Arponen [13]; that is, the first derivative of the objective function is characterized by a decreasing function. This extends demand to a generally non-increasing function.

We know that solving $\frac{d}{d T} \pi(T)=0$ is equivalent to solving $H(T)=0$.

Owing to $\lim _{T \rightarrow 0} H(T)=K>0$, we assume an auxiliary notation

$$
\lim _{T \rightarrow \min \left\{T_{0},(p-c) / h\right\}} H(T)=\Omega .
$$

We consider two cases: (a) $\Omega \geq 0$ and (b) $\Omega<0$.

For Case (a), $\frac{d}{d T} \pi(T)>0$ for $0<T<\min \left\{T_{0},(p-c) / h\right\}$ so that $\pi(T)$ is an increasing function attaining its maximum at the right boundary, $\min \left\{T_{0},(p-c) / h\right\}$. 
For Case (b), $\Omega<0$, we know that $\frac{d}{d T} \pi(T)$ is decreasing from $\lim _{T \rightarrow 0} \frac{d}{d T} \pi(T)>0$ to $\lim _{T \rightarrow \min \left\{T_{0},(p-c) / h\right\}^{d T}} \frac{d}{d T} \pi(T)=\Omega<0$, such that there exists a unique point $T^{*}$ with $\left.\frac{d}{d T} \pi(T)\right|_{T^{*}}=0$; that is, $H\left(T^{*}\right)=0$. We find that $\frac{d}{d T} \pi(T)>0$ for $0<T<T^{*}$ and $\frac{d}{d T} \pi(T)<0$ for $T^{*}<T<\min \left\{T_{0},(p-c) / h\right\}$. Hence, $\pi(T)$ increases for $0<T<T^{*}$ and decreases for $T^{*}<T<\min \left\{T_{0},(p-c) / h\right\}$. This implies that $T^{*}$ represents the global maximum point.

We summarize these findings in the following theorem:

Theorem 1. We extended the inventory model of Avinadav and Arponen [13] from a polynomial type demand to any non-increasing demand, to derive two cases:

(a) If $\Omega \geq 0$, then the maximum point will occur at the boundary point, $\min \left\{T_{0},(p-c) / h\right\}$.

(b) If $\Omega<0$, then $T^{*}$ is the maximum point with $H\left(T^{*}\right)=0$.

We can change the order of integration to imply that:

$$
\int_{t=0}^{T} \int_{s=t}^{T} \lambda(s) d s d t=\int_{s=0}^{T} \int_{t=0}^{s} \lambda(s) d t d s .
$$

This yields

$$
\int_{t=0}^{T} \int_{s=t}^{T} \lambda(s) d s d t=\int_{s=0}^{T} s \lambda(s) d s
$$

Moreover, we assume auxiliary function $f(s)$ where

$$
f(s)=[(p-c)-h s] \lambda(s) .
$$

We know that $f(s)$ is a decreasing function with $f(s)>0$ for $s \in(0, T)$ and for new expression $L(T)$,

$$
L(T)=K+T \lambda(T)[(p-c)-h T]-\int_{0}^{T} f(s) d s .
$$

We find that

$$
\Omega=\lim _{T \rightarrow \min \left\{T_{0},(p-c) / h\right\}} L(T) .
$$

In the above, $K$ is ordering cost; $p$ is selling price; $c$ is purchasing cost; $h$ is holding cost per unit time; and $(p-c)-h s$ is the net profit for one item with store period $[0, s]$. If amount $\lambda(s) \Delta s$ is the demand during $[s, s+\Delta s]$, then this implies that $[(p-c)-h s] \lambda(s) \Delta s$ is the accumulated net profit during $[s, s+\Delta s]$ and $\int_{0}^{T}[(p-c)-h s] \lambda(s) d s$ is the accumulated net profit during $[0, T] . T \lambda(T)[(p-c)-h T]$ then indicates the accumulated net profit during the whole time interval $[0, T]$ with stable demand $\lambda(T)$.

Hence, $\Omega$ represents the difference between (a) the sum of the ordering cost and a stable demand accumulated net profit and (b) the accumulated net profit with decreasing demand.

\section{Applying the Proposed Approach to Models of Avinadav and Arponen (2009) and Avinadav et al. (2014)}

Based on Equation (16), we can prove $\frac{d}{d T} H(T)<0$ by showing

$$
(p-c-h T) \frac{d \lambda(T)}{d T}-h \lambda(T)<0 .
$$

If we consider the demand of Avinadav and Arponen [13] of Equation (1), then

$$
\frac{d}{d T} \lambda(T)=\lambda_{0} n\left(1-\frac{T}{T_{0}}\right)^{n-1}\left(\frac{-1}{T_{0}}\right)
$$


If we substitute Equation (25) into Equation (24), and substitute Equation (1) into Equation (24) and then cancel $\frac{\lambda_{0}}{h}\left(1-\frac{T}{T_{0}}\right)^{n-1}$ from both sides of the inequality, we show that Equation (24) is equivalent to

$$
\left(\frac{p-c}{h}-T\right) n\left(\frac{-1}{T_{0}}\right)<\left(1-\frac{T}{T_{0}}\right) .
$$

This inequality can be directly verified, because $T<\frac{p-c}{h}$ and $T<T_{0}$. Moreover, we can simplify it to separate variable $T$ with the constant term. Then,

$$
(n+1) T<T_{0}+n \frac{p-c}{h} .
$$

If we divide this by $n+1$, we obtain

$$
T<T_{1}=\frac{T_{0}+n((p-c) / h)}{n+1} .
$$

The above discussion shows that the claim made by Avinadav and Arponen [13], in which $T$ is less than the linear combination of upper bounds $T_{0}$ and $(p-c) / h$, is not an astonishing result. Hence, we illustrate that the model of Avinadav and Arponen [13] is a special case of the model proposed in this paper.

In Avinadav et al. [14], polynomial demand is expressed as

$$
\lambda(t, p)=\lambda_{0}(1-\alpha p)\left[1-\left(\frac{t}{E}\right)^{n}\right]
$$

$t \leq E$ and $\alpha p \leq 1$ to include a new variable, price $p$. To apply our derivation to Avinadav et al. [14], the variable $p$ should be treated as a constant with $\Gamma_{0}=\lambda_{0}(1-\alpha p)$. This gives

$$
\lambda(t)=\Gamma_{0}\left[1-\left(\frac{t}{E}\right)^{n}\right]
$$

for $t \leq E$.

If we substitute the demand of Equation (30) into Equation (24), then $\frac{d}{d T} H(T)<0$ is equivalent to prove

$$
(p-c-h T) \Gamma_{0} \frac{n}{E}\left(\frac{T}{E}\right)^{n-1}+h \Gamma_{0}\left[1-\left(\frac{T}{E}\right)^{n}\right]>0 .
$$

We know that the inequality of Equation (31) is valid such that we illustrate that our derivation can be applied for Avinadav et al. [14].

\section{Numerical Examples}

Two conditions must be examined to find the optimal solution: (a) $\min \left\{T_{0},(p-c) / h\right\}$, and (b) the sign of $\Omega$. Hence, we present four examples:

Example 1. $\min \left\{T_{0},(p-c) / h\right\}=(p-c) / h$, and $\Omega \geq 0$.

Example 2. $\min \left\{T_{0},(p-c) / h\right\}=T_{0}$, and $\Omega \geq 0$.

Example 3. $\min \left\{T_{0},(p-c) / h\right\}=(p-c) / h$, and $\Omega<0$.

Example 4. $\min \left\{T_{0},(p-c) / h\right\}=T_{0}$, and $\Omega<0$.

Based on Avinadav and Arponen [13], we construct numerical examples with the following parameters: selling price $p=2$ and purchasing cost $c=1$. For general nonincreasing demand, we adopt exponential decreasing demand $\lambda(t)=D_{0} e^{-\alpha t}$ for $0 \leq t \leq$ $\min \left\{T_{0},(p-c) / h\right\}$ with $D_{0}=20$ and $\alpha=0.01$. The parameters of holding cost $h$, ordering $\operatorname{cost} K$, and shelf-life period $T_{0}$ are listed in Table 2 for Examples 1-4. 
Table 2. Parameters for $h, K$, and $T_{0}$ as well as for derived $\Omega$ and $T^{*}$.

\begin{tabular}{cccccccc}
\hline Ex. & $\boldsymbol{h}$ & $\boldsymbol{K}$ & $\boldsymbol{T}_{0}$ & $(\boldsymbol{p}-\boldsymbol{c}) / \boldsymbol{h}$ & $\left.\boldsymbol{\operatorname { m i n }}\left\{\boldsymbol{T}_{0}, \boldsymbol{p}-\boldsymbol{c}\right) / \boldsymbol{h}\right\}$ & $\boldsymbol{\Omega}$ & $\boldsymbol{T}^{*}$ \\
\hline 1 & 0.05 & 200 & 30 & 20 & $(p-c) / h=20$ & 12.7 & 20 \\
\hline 2 & 0.5 & 7 & 1 & 2 & $T_{0}=1$ & 1.97 & 1 \\
\hline 3 & 0.05 & 50 & 30 & 20 & $(p-c) / h=20$ & -137.3 & 9.6893 \\
\hline 4 & 0.02 & 50 & 30 & 50 & $T_{0}=30$ & -142.8 & 13.9555 \\
\hline
\end{tabular}

For Example 1, because $(p-c) / h=20<T_{0}=30$, we find $\Omega=H(20)=12.7>0$. According to Theorem 1 (a), we know the optimal replenishment cycle $T^{*}=20$ and maximum profit $\pi(20)=-0.63462$. For the sake of completeness, we list several related profits in Table 3 to illustrate that $T^{*}=20$ is the optimal solution.

Table 3. Related profits for Example 1.

\begin{tabular}{cccccc}
\hline$T$ & 1 & 5 & 10 & 15 & 20 \\
\hline$\pi(T)$ & -180.59635 & -22.90998 & -5.64632 & -1.55161 & -0.63462 \\
\hline
\end{tabular}

It may seem unreasonable that the maximum profit in Example 1 is negative. Hence, we show that when $\Omega \geq 0$ and $(p-c) / h<T_{0}$, the optimal maximum profit is always non-positive.

By Equation (10), with $\lambda(t)=D_{0} e^{-\alpha t}$ for $0 \leq t \leq \min \left\{T_{0},(p-c) / h\right\}$, we obtain

$$
\pi(T)=\frac{K(T)}{T}
$$

and

$$
H(T)=T(p-c-h T) D_{0} e^{-\alpha T}-K(T)
$$

where

$$
K(T)=\left[(p-c) \frac{D_{0}}{\alpha}\left(1-e^{-\alpha T}\right)-K-\frac{h D_{0}}{\alpha^{2}}\left(1-e^{-\alpha T}-\alpha T e^{-\alpha T}\right)\right]
$$

is an auxiliary function to simplify the expression.

Under the conditions of $(p-c) / h<T_{0}$ and $\Omega=H((p-c) / h) \geq 0$, using Equation (33), we find that $H((p-c) / h)=-K((p-c) / h) \geq 0$. Then, optimal profit is derived

$$
\pi((p-c) / h)=\frac{K((p-c) / h)}{(p-c) / h} \leq 0 .
$$

This verifies that the maximum profit is always non-positive. For a private company, this scenario will result in the disposal of inventory. However, for the public sector, projects operating at a loss may still serve to benefit society as a whole. We summarize our findings in the following theorem.

Theorem 2. Under conditions $(p-c) / h<T_{0}$ and $\Omega=H((p-c) / h) \geq 0$, non-positive profit $\pi((p-c) / h)$ satisfies

$$
\pi((p-c) / h)=-\frac{H((p-c) / h)}{((p-c) / h)} \leq 0
$$

For Example 2, because $T_{0}=1<(p-c) / h=2$, we find $\Omega=H(1)=1.97>0$. Theorem 1 (a) gives us an optimal replenishment cycle $T^{*}=1$ and maximum profit $\pi(1)=7.93354$. For the sake of completeness, we list several related profits in Table 4 to illustrate that $T^{*}=1$ is the optimal solution. 
Table 4. Related profits for Example 2.

\begin{tabular}{cccccc}
\hline$T$ & 0.3 & 0.5 & 0.7 & 0.9 & 1 \\
\hline$\pi(T)$ & -4.86031 & 3.45840 & 6.44645 & 7.65940 & 7.93354 \\
\hline
\end{tabular}

For Example 3, because $(p-c) / h=20<T_{0}=30$, we find $\Omega=H(20)=-137.3<0$. According to Theorem 1 (b), there exists a unique solution of $H(T)=0$, for $0<T<20$ where $H(T)$ is a decreasing function from $\lim _{T} H(0)=\infty$ to $H(20)<0$. Through bisection, we find the optimal replenishment cycle $T^{*}=9.6893$ and maximum profit $\pi\left(T^{*}\right)=9.35850$. For the sake of completeness, we list several related profits in Table 5 to illustrate that $T^{*}=9.6893$ is the optimal solution.

Table 5. Related profits for Example 3.

\begin{tabular}{cccccc}
\hline$T$ & 9.6 & 9.68 & 9.6893 & 9.69 & 9.7 \\
\hline$\pi(T)$ & 9.35808 & 9.35849362 & 9.35849813 & 9.35849811 & 9.35849227 \\
\hline
\end{tabular}

For Example 4, because $T_{0}=30<(p-c) / h=50$, we find $\Omega=H(30)=-142.8<0$. According to Theorem 1 (b), there exists a unique solution for $H(T)=0$ with $0<T<30$. Through bisection, we find the optimal replenishment cycle $T^{*}=13.9555$ and maximum profit $\pi\left(T^{*}\right)=12.53983$. For the sake of completeness, we list several related profits in Table 6 to illustrate that $T^{*}=13.9555$ is the optimal solution.

Table 6. Related profits for Example 4.

\begin{tabular}{cccccc}
\hline$T$ & 13.9 & 13.95 & 13.9555 & 13.96 & 14.0 \\
\hline$\pi(T)$ & 12.53977 & 12.53982 & 12.53983 & 12.53982 & 12.53979 \\
\hline
\end{tabular}

These examples demonstrate all possible cases that may occur concerning (i) the interior maximum point and boundary maximum point as well as (ii) the comparison between $T_{0}$ and $(p-c) / h$. However, for all these examples, $\lim _{t \rightarrow T_{0}} \lambda(t) \neq 0$. For certain products, demand will drop to zero before the expiry date. For example, when buying powdered milk, parents might worry that the milk will have expired before their infant uses all the product. Hence, we provide another four examples with $\lim _{t \rightarrow T_{0}} \lambda(t)=0$ where $T_{0}$ is up to a month before the expiry date. We refer to Avinadav and Arponen [13] to construct our examples, using the following parameters: $T_{0}=30, \lambda_{0}=100, n=1, c=\$ 1$, $p=\$ 2, h=\$ 0.05$, and $K=\$ 50$. We modify these slightly to construct four different cases, as follows:

Example 5. $\min \left\{T_{0},(p-c) / h\right\}=(p-c) / h$, and $\Omega<0$, with $T_{0}=30$.

Example 6. $\min \left\{T_{0},(p-c) / h\right\}=T_{0}$, and $\Omega<0$, with $T_{0}=30$.

Example 7. $\min \left\{T_{0},(p-c) / h\right\}=(p-c) / h$, and $\Omega \geq 0$, with $T_{0}=4$.

Example 8. $\min \left\{T_{0},(p-c) / h\right\}=T_{0}$, and $\Omega \geq 0$, with $T_{0}=3$.

These parameters and their corresponding results are listed in Table 7.

Table 7. Modified parameters for Examples 5-8 and optimal solutions.

\begin{tabular}{ccccccc}
\hline Ex. & $\boldsymbol{T}_{0}$ & $\boldsymbol{h}$ & $\boldsymbol{K}$ & $\boldsymbol{\Omega}$ & $\boldsymbol{T}^{*}$ & $\boldsymbol{\pi}\left(\boldsymbol{T}^{*}\right)$ \\
\hline 5 & 30 & 0.05 & 50 & -727.778 & 3.646 & 71.833192 \\
\hline 6 & 30 & 0.02 & 50 & $\begin{array}{c}-1.15 \times \\
10^{3}\end{array}$ & 4.502 & 77.33889172 \\
\hline 7 & 4 & 0.27 & 150 & 21.971 & 3.704 & -5.932099 \\
\hline 8 & 3 & 0.27 & 150 & 40.5 & 3 & -13.5 \\
\hline
\end{tabular}


To confirm the optimality of our solutions for Examples 5-8, we ran a comparison test near the proposed solutions, which are listed in Table 8.

Table 8. Comparisons near the optimal solution for Examples 5-8.

\begin{tabular}{ccccc}
\hline Ex. 5 & $T$ & 3.645 & 3.646 & 3.647 \\
\hline & $H(T)$ & 0.022 & $-3.547 \times 10^{-3}$ & -0.03 \\
\hline Ex. 6 & $\pi(T)$ & 71.833191 & 71.833192 & 71.833191 \\
\hline & $T$ & 4.501 & 4.502 & 4.503 \\
\hline Ex. 7 & $H(T)$ & 0.029 & $7.392 \times 10^{-3}$ & -0.014 \\
\hline & $\pi(T)$ & 77.33889100 & 77.33889172 & 77.33889156 \\
\hline Ex. 8 & $T$ & 3.700 & 3.702 & 3.704 \\
\hline & $\pi(T)$ & -5.938041 & -5.934830 & -5.932099 \\
\hline & $T$ & 2.8 & 2.9 & 3.0 \\
\hline
\end{tabular}

For Example 5, our result is the same as that of Avinadav and Arponen [13]. The result for Example 7 supports Theorem 2. Examples 7 and 8 illustrate that the maximum point can occur at the boundary; this was overlooked by Avinadav et al. [18].

\section{Direction for Future Research and Managerial Insights}

There are three papers: Sarkar [47], Sarkar [48], and Sepehri et al. [49] that are worth mentioning for the direction of future research. Sarkar [47] developed a maximized profit model for deteriorated items where the deterioration rate is a reciprocal of a linear function and the demand is a quadratic polynomial function of time. In his model, the suppliers offered a trade-credit offer to the retailers. Based on Sarkar [47], in the future, we may try to extend our inventory model with deteriorated items and a trade-credit offer provided by the suppliers to the retailers. Sarkar [48] proposed a production-inventory model with deteriorating items in a two-echelon supply chain environment. His goal was to find the minimum cost for the supply chain by algebraic methods. Deterioration cost, transportation cost, and handling cost are included in his model. Based on Sarkar [48], we may try to generalize our inventory model with deterioration cost, transportation cost, and handling cost. Sepehri et al. [49] considered deteriorating inventory models with shelf life, delay in payment, and carbon emissions. They tried to find the optimal replenishment cycle, selling price, and carbon reduction investment. Based on Sepehri et al. [49], in the future, we may try to extend our inventory model with deteriorated items, payment delays, and carbon emissions.

Based on Theorem 2, if two conditions are satisfied then the optimal profit value must be negative to indicate a distinct character of our inventory model. For private companies, if the maximum profit is negative, then the companies will give up this replenishment policy to avoid financial loss. However, for public service environments, to fulfill citizens' daily requirements, some organizations with a bottomless pit for money are running to perform government duty and canvassing voters. Our model may be provided a proper description for these kinds of phenomenons.

Managerial insights of our manuscript are described as follows. We find conditions to help decision-makers to decide the interior optimal solution or the boundary optimal solution where the boundary optimal solution was overlooked by Avinadav and Arponen [13]. Our Theorem 2 shows that the maximum profit is always negative that was supported by numerical Examples 1 and 7. On the other hand, Avinadav and Arponen [13] had only one example that is our numerical Example 5. In Appendix D of Avinadav and Arponen [13], they mentioned that they solved 729 different numerical examples and then only 474 of them end with a positive profit. For those 474 numerical examples, Avinadav 
and Arponen [13] studied the sensitivity analysis and then listed the average derivation in the Table D1 of Avinadav and Arponen [13]. We can claim that Avinadav and Arponen [13] did not know these kinds of inventory models under the condition of Theorem 2 will result in a negative profit. They arbitrarily neglected those numerical examples with negative maximum profit values. Our approach points out that under the condition of Theorem 2, the negative maximum profit is a valid finding.

\section{Conclusions}

The significant finding of our paper is to point out that sometimes a negative maximum profit model is reasonable which is verified by our Theorem 2 . In this paper, we extend the inventory model of Avinadav and Arponen [13]. We provide a reasonable explanation for the linear combination of two upper bounds that appeared in the derivation of Avinadav and Arponen [13] and further identify a condition for boundary optimal solutions. We also show that for some cases, the boundary maximum value is always negative. For the applicability of the model, we believe that some public sections with financial loss will adopt our model to describe their real-life situation to reflect the results of negative maximum profit. For the direction for future research if this can be justified would it not be better to model using a probabilistic approach such as with probability pi an arriving demand will accept the product whose demand is i units away from expiring? To derive a negative maximum profit value appear SASA failed development. However, if in the future, some social and humanitarian considerations are combined with our proposed model, then the maximum profit may be changed to a positive value. These findings lay the foundation for the development of sound inventory models in the future. For limitations of our paper, in our present version, we did not consider the following factors: deterioration cost, transportation cost, handling cost, payment delays, and carbon emissions. In the future, we will consider developing new inventory models to contain some of the above factors to modify our system to a more general setting.

Author Contributions: Conceptualization, K.-C.H. and G.K.Y.; methodology, H.-W.T.; software, H.-W.T. and K.-C.H.; validation, H.-W.T., K.-C.H. and G.K.Y.; formal analysis, H.-W.T., K.-C.H. and G.K.Y.; investigation, H.-W.T. and K.-C.H.; resources, H.-W.T. and K.-C.H.; data curation, H.-W.T. and K.-C.H.; writing—original draft preparation, H.-W.T. and G.K.Y.; writing—review and editing, H.-W.T. and G.K.Y.; visualization, H.-W.T.; supervision, G.K.Y.; project administration, H.-W.T. and K.-C.H.; funding acquisition, H.-W.T. and K.-C.H. All authors have read and agreed to the published version of the manuscript.

Funding: This research received no external funding.

Data Availability Statement: Not applicable.

Conflicts of Interest: The authors declare no conflict of interest.

\section{References}

1. Sarkar, B.; Ahmed, W.; Choi, S.B.; Tayyab, M. Sustainable inventory management for environmental impact through partial backordering and multi-trade-credit-period. Sustainability 2018, 10, 4761. [CrossRef]

2. Quezada-Téllez, L.A.; Fernández-Anaya, G.; Brun-Battistini, D.; Nuñez-Zavala, B.; Macías-Díaz, J.E. An economic model for OECD economies with truncated M-derivatives: Exact solutions and simulations. Mathematics 2021, 9, 1780. [CrossRef]

3. Lee, Z.Y.; Chu, M.T.; Wang, Y.T.; Chen, K.J. Industry performance appraisal using improved MCDM for next generation of Taiwan. Sustainability 2020, 12, 5290. [CrossRef]

4. Zimpel-Leal, K.; Lettice, F. Generative mechanisms for scientific knowledge transfer in the food industry. Sustainability 2021, 13, 955. [CrossRef]

5. Rubio-Valdehita, S.; Rodríguez-López, A.M.; Marín, A. Concern about the Effects of the Pandemic Caused by COVID-19 in the Retail Sector in Spain. Differences between Men and Women. Med. Sci. Forum 2021, 4, 9. [CrossRef]

6. Górska-Warsewicz, H.; Żakowska-Biemans, S.; Stangierska, D.; Świåtkowska, M.; Bobola, A.; Szlachciuk, J.; Czeczotko, M.; Krajewski, K.; Świstak, E. Factors limiting the development of the organic food sector-Perspective of processors, distributors, and retailers. Agriculture 2021, 11, 882. [CrossRef]

7. Gładysz, B.; Buczacki, A.; Haskins, C. Lean management approach to reduce waste in HoReCa food services. Resources 2020, 9 , 144. [CrossRef] 
8. Orynycz, O.; Tucki, K.; Prystasz, M. Implementation of lean management as a tool for decrease of energy consumption and CO2 emissions in the fast food restaurant. Energies 2020, 13, 1184. [CrossRef]

9. De Giovanni, P. Digital supply chain through dynamic inventory and smart contracts. Mathematics 2019, 7, 1235. [CrossRef]

10. Malik, A.I.; Sarkar, B. Coordinating supply-chain management under stochastic fuzzy environment and lead-time reduction. Mathematics 2019, 7, 480. [CrossRef]

11. Lin, J.; Chao, H.C.J.; Julian, P. Planning horizon for production inventory models with production rate dependent on demand and inventory level. J. Appl. Math. 2013, 2013, 961258. [CrossRef]

12. Yang, G.K.L.; Chou, S.Y.; Hung, C.Y.; Lin, S.J.; Chu, P. Research note on the criteria for the optimal solution of the inventory model with a mixture of partial backordering and lost sales. Appl. Math. Model. 2008, 32, 1758-1768. [CrossRef]

13. Avinadav, T.; Arponen, T. An EOQ model for items with a fixed shelf-life and a declining demand rate based on time-to-expiry technical note. Asia Pac. J. Oper. Res. 2009, 26, 759-767. [CrossRef]

14. Avinadav, T.; Herbon, A.; Spiegel, U. Optimal inventory policy for a perishable item with demand function sensitive to price and time. Int. J. Prod. Econ. 2013, 144, 497-506. [CrossRef]

15. Leśniewski, P.; Bartoszewicz, A. LQ optimal sliding mode control of periodic review perishable inventories with transportation losses. Math. Probl. Eng. 2013, 2013, 325274. [CrossRef]

16. Aiello, G.; Enea, M.; Muriana, C. Economic benefits from food recovery at the retail stage: An application to Italian food chains. Waste Manag. 2014, 34, 1306-1316.

17. Avinadav, T. On real-time accounting of inventory costs in the newsvendor model and its effect on the service level. J. Serv. Sci. Manag. 2014, 7, 45183. [CrossRef]

18. Avinadav, T.; Herbon, A.; Spiegel, U. Optimal ordering and pricing policy for demand functions that are separable into price and inventory age. Int. J. Prod. Econ. 2014, 155, 406-417. [CrossRef]

19. Herbon, A. Dynamic pricing vs. acquiring information on consumers heterogeneous sensitivity to product freshness. Int. J. Prod. Res. 2014, 52, 918-933. [CrossRef]

20. Aiello, G.; Enea, M.; Muriana, C. Alternatives to the traditional waste management: Food recovery for human non-profit organizations. Int. J. Oper. Quant. Manag. 2015, 21, 101-125.

21. Chuang, K.W.; Lin, C.N. Replenishment policies for deteriorating items with ramp type demand and a fixed shelf-life under shortage. J. Netw. 2015, 10, 470-476. [CrossRef]

22. Ma, P. Ordering and pricing strategies for fresh products with multiple quality levels considering consumer utility. Am. J. Oper. Res. 2015, 5, 56444. [CrossRef]

23. Muriana, C. Effectiveness of the food recovery at the retailing stage under shelf life uncertainty: An application to Italian food chains. Waste Manag. 2015, 41, 159-168. [CrossRef]

24. Avinadav, T. Stochastic periodic-review models with duration- and quantity-dependent inventory costs: Properties and approximations. Asia Pac. J. Oper. Res. 2016, 33, 1650030. [CrossRef]

25. Muriana, C. An EOQ model for perishable products with fixed shelf life under stochastic demand conditions. Eur. J. Oper. Res. 2016, 255, 388-396. [CrossRef]

26. Yamazaki, T.; Shida, K.; Kanazawa, T. An approach to establishing a method for calculating inventory. Int. J. Prod. Res. 2016, 54, 2320-2331. [CrossRef]

27. Avinadav, T.; Chernonog, T.; Lahav, Y.; Spiegel, U. Dynamic pricing and promotion expenditures in an EOQ model of perishable products. Ann. Oper. Res. 2017, 248, 75-91. [CrossRef]

28. Demirag, O.C.; Kumar, S.; Rao, K.S.M. A note on inventory policies for products with residual-life-dependent demand. Appl. Math. Model. 2017, 43, 647-658. [CrossRef]

29. Muriana, C. A focus on the state of the art of food waste/losses issue and suggestions for future researches. Waste Manag. 2017, 68, 557-570. [CrossRef]

30. Sharma, S.; Singh, S.; Singh, S.R. An inventory model for deteriorating items with expiry date and time varying holding cost. Int. J. Procure. Manag. 2018, 11, 650-666. [CrossRef]

31. Chernonog, T.; Avinadav, T. Pricing and advertising in a supply chain of perishable products under asymmetric information. Int. J. Prod. Econ. 2019, 209, 249-264. [CrossRef]

32. Hanukov, G.; Avinadav, T.; Chernonog, T.; Yechiali, U. Performance improvement of a service system via stocking perishable preliminary services. Eur. J. Oper. Res. 2019, 274, 1000-1011. [CrossRef]

33. Lin, Z.; Jun, T.; Fung, R.Y.K.; Dang, C. Materials procurement and reserves policies for humanitarian logistics with recycling and replenishment mechanisms. Comput. Ind. Eng. 2019, 127, 709-721.

34. Avinadav, T. The effect of decision rights allocation on a supply chain of perishable products under a revenue-sharing contract. Int. J. Prod. Econ. 2020, 225, 107587. [CrossRef]

35. Chernonog, T. Inventory and marketing policy in a supply chain of a perishable product. Int. J. Prod. Econ. 2020, 219, 259-274. [CrossRef]

36. Hanukov, G.; Avinadav, T.; Chernonog, T.; Yechiali, U. A service system with perishable products where customers are either fastidious or strategic. Int. J. Prod. Econ. 2020, 228, 107696. [CrossRef]

37. Krommyda, I.P.; Tatsis, V.; Skouri, K. Optimal ordering and disposal decisions for products with a fixed shelf life. RAIRO-Oper. Res. 2020, 54, 1453-1465. [CrossRef] 
38. Muriana, C. Inventory management policy for perishable products with Weibull deterioration and constrained recovery assumption based on the residual life. Int. J. Oper. Res. 2020, 39, 516-538. [CrossRef]

39. Hanukov, G.; Avinadav, T.; Chernonog, T.; Yechiali, U. A multi-server system with inventory of preliminary services and stock-dependent demand. Int. J. Prod. Res. 2021, 59, 4384-4402. [CrossRef]

40. Bhuiya, S.K.; Ghosh, D.; Chakraborty, D. On the distribution-free continuous review (Q, r, L) inventory model with lead-timedependent partial backlogging. Int. J. Manag. Sci. Eng. Manag. 2019, 14, 273-283. [CrossRef]

41. Ganguly, B.; Sarkar, B.; Sarkar, M.; Pareek, S.; Omair, M. Influence of controllable lead time, premium price, and unequal shipments under environmental effects in a supply chain management. RAIRO Oper. Res. 2019, 53, 1427-1451. [CrossRef]

42. Hota, S.K.; Sarkar, B.; Ghosh, S.K. Effects of unequal lot size and variable transportation in unreliable supply chain management. Mathematics 2020, 8, 357. [CrossRef]

43. Khan, M.; Jaber, M.Y.; Zanoni, S.; Zavanella, L. Vendor managed inventory with consignment stock agreement for a supply chain with defective items. Appl. Math. Model. 2016, 40, 7102-7144. [CrossRef]

44. Kim, M.S.; Kim, J.S.; Sarkar, B.; Sarkar, M.; Iqbal, M.W. An improved way to calculate imperfect items during long-run production in an integrated inventory model with backorders. J. Manuf. Syst. 2018, 47, 153-167. [CrossRef]

45. Mishra, U.; Wu, J.-Z.; Sarkar, B. A sustainable production-inventory model for a controllable carbon emissions rate under shortages. J. Clean. Prod. 2020, 256, 120268. [CrossRef]

46. Taleizadeh, A.A.; Kalantari, S.S.; Cárdenas-Barrón, L.E. Pricing and lot sizing for an EPQ inventory model with rework and multiple shipments. TOP 2016, 24, 143-155. [CrossRef]

47. Sarkar, B. An EOQ model with delay in payments and time varying deterioration rate. Math. Comput. Model. 2012, 55, 367-377. [CrossRef]

48. Sarkar, B. A production-inventory model with probabilistic deterioration in two-echelon supply chain management. Appl. Math Model. 2013, 37, 3138-3151. [CrossRef]

49. Sepehri, A.; Mishra, U.; Tseng, M.-L.; Sarkar, B. Joint Pricing and Inventory Model for Deteriorating Items with Maximum Lifetime and Controllable Carbon Emissions under Permissible Delay in Payments. Mathematics 2021, 9, 470. [CrossRef] 